\title{
JNPH
}

Volume 7 No. 1 (April 2019)

(C) The Author(s) 2019

\section{PENGARUH EDUKASI MENSTRUASI MELALUI WHATSAPP TERHADAP SELF CARE DISMENORE PADA REMAJA PUTRI SMA DI KOTA BENGKULU}

\section{THE EFFECT OF MENSTRUATION EDUCATION THROUGH WHATSAPP ON SELF CARE DISMENORE IN ADOLESCENT HIGH SCHOOL PRIVATE VOCATIONAL SCHOOL IN BENGKULU CITY}

\author{
NEHRU NUGROHO ${ }^{1}$, IDA HARTATI ${ }^{2}$, WULANDARI ${ }^{3}$, ASMAWATI $^{4}$ \\ POLITEKNIK KESEHATAN KEMENTERIAN KESEHATAN BENGKULU ${ }^{1,3,4}$ \\ PUSKESMAS SAWAH LEBAR KOTA BENGKULU \\ Email: 84nehru.nugroho@gmail.com
}

\begin{abstract}
ABSTRAK
Dismenore yang tidak ditangani mengakibatkan gangguan saat aktifitas sehari-hari, retrograd menstruasi, infertilitas (kemandulan), kehamilan ektopik tidak terdeteksi, dan infeksi. Tujuan penelitian ini untuk mengetahui pengaruh edukasi menstruasi melalui whatsapp terhadap self care dismenore pada remaja SMA Kota Bengkulu.Desain penelitian quasi eksperimental dengan pre-test and post-test with control group design. Jumlah sampel 70 orang terdiri dari 35 kelompok kontrol dan 35 kelompok intervensi. Teknik sampling adalah simple random sampling. Pengukuran self care dismenore menggunakan ADSCS yang terdiri dari 35 pertanyaan, Analisis menggunakan Mann-Whitney pada $\alpha<5 \%$. Hasil penelitian menunjukkan bahwa rata-rata self care dismenore pada kelompok kontrol sebelum di berikan edukasi WhatsApp 131,17 dan pada kelompok intervensi 133,71. Setelah dilakukan edukasi WhatsApp pada kelompok kontrol rata-rata self care dismenore 134,57 dan pada kelompok intervensi $150,09(p=0.000)$. WhatsApp dapat digunakan sebagai salah satu media edukasi tentang self care dismenore. Edukasi melalui WhatsApp dapat meningkatkan self care dismenore.
\end{abstract}

Kata kunci : Edukasi, Dismenore,WhatsApp, self care

\begin{abstract}
Untreated dysmenorrhea results in impaired daily activities, retrograde menstruation, infertility, undetectable ectopic pregnancy, and infection. The purpose of this research was to investigate the effect of menstrual education through whatsapp toward self-care of dysmenorrhea on teenage girls of senior high school in Bengkulu city. The research method was quasi experimental with pre and post test with control group design. The sample consisted of 70 people. There were 35 people of control group and 35 people of intervention group. The technique of sampling was simple random sampling. Measurement of self-care of dysmenorrhea was using ADSCS consisting of 35 questions. Mann-Whitney at $\alpha<5 \%$ used to analyze the data. The results shows that the average of self-care dysmenorrhea in the control group before given education through WhatsApp was 131,17 and the intervention group was 133,71 After given education through WhatsApp in the control group, the average of self-care
\end{abstract}


dysmenorrhea was 134,57 and in the intervention group was $150,09(p=0.000)$. WhatsApp can be used as one of educational media concerning self-care of dysmenorrhea. Education through WhatsApp can improved self-care of dysmenorrhea.

\section{Keyword : Education, Dysmenorrhea,WhatsApp, Self-Care}

\section{PENDAHULUAN}

Dismenore dibedakan menjadi dismenore primer dan dismenore sekunder. Dismenore primer merupakan kelainan umum yang ditandai dengan nyeri/kram pada rahim yang menyakitkan, sesaat atau selama menstruasi yang tidak diakibatkan karena kondisi patologis pelvis (Polat et al., 2009), sedangkan dismenore sekunder mengacu pada nyeri haid yang terjadi akibat dari penyakit seperti endometriosis, penyumbatan dan penyakit radang panggul (Cry et al., 2003).

Dampak yang akan terjadi jika nyeri haid dismenorhea) yang tidak ditangani adalah gangguan aktifitas hidup sehari-hari, retrograd menstruasi (menstruasi yang bergerak mundur), infertilitas (kemandulan), kehamilan ektopik tidak terdeteksi, pecahnya kista, dan infeksi. Dampak psikologis yang dialami antara lain konflik emosional, ketegangan dan kegelisahan,perasaan yang tidak nyaman dan perasaan terisolasi (Paramita, 2010 dalam Purba, Rompas, \& Karundeng, 2014).

Peneltian Wong, et al., 2015 di Hongkong menunjukkan bahwa remaja putri jarang sekali berkonsultasi dengan tenaga kesehatan dan mencari Aktifitas fisik seperti olahraga atau gerakan saran medis untuk pengobatan dismenore dan lebih memilih perawatan diri secara mandiri (self care dismenore) untuk meringankan nyeri haidnya (Lau et al 2000, Leeet al. 2006, Cheng \& Lin 2010). Perempuan dari negaranegara Barat juga lebih memilih perawatan mandiri untuk menangani dismenore nya (Agarwal \& Venkat, 2009). Self care dismenore ini merupakan studi yang memberikan informasi tentang perawatan mandiri dan perilaku perawatan diri remaja selama dismenore (Baker \& Denyes, 2008). Model self care (perawatan diri) ini memiliki nilai dan keyakinan yang ada dalam keperawatan sesuai kemampuan klien. Model perawatan mandiri ini dapat meredakan dismenore (Cheng \& Lin, 2010; Wong \& Ip, 2012; Wong, Lai, \& Tse, 2010).

Penelitian Lamadah dan Al Zamil (2014) tentang praktek self care dismenore pada remaja putri menggambarkan $87,2 \%$ remaja putri mengalami nyeri menstruasi dan bahkan $47,5 \%$ remaja putri sampai mengalami gangguan psikososial seperti ansietas, depresi dan perubahan mood karena dismenore. Dari $87,2 \%$ yang mengalami dismenore, $72,7 \%$ melakukan perawatan diri saat dismenore dengan minum air hangat 48,91\% menggunakan obat analgesik atau antispasmodik untuk meredakannya rasa sakit, $35,77 \%$ memilih istirahat dan tidur tanpa melakukan aktivitas, hanya $21,16 \%$ berolahraga saat menstruasi, 20,0\% mandi air hangat, serta $16,78 \%$ berkonsultasi dengan tenaga kesehatan dan mengunjungi dokter. Terkait praktik self care dismenore 34\% remaja putri yang mengalami dismenore melakukan praktik self care dismenore yang tidak lengkap dan $24,7 \%$ melakukan praktik yang salah.

Berdasarkan penelitian diatas maka sangat penting sekali untuk mengajarkan bagaimana self care atau perawatan diri secara mandiri dalam mengatasi dan mengurangi nyeri haid atau dismenore. Survey awal dilakukan peneliti melalui wawancara pada beberapa remaja putri di SMA negeri 07 dan SMAN 06 kota Bengkulu didapatkan dari 10 orang responden, 10 remaja putri $(100 \%)$ menyatakan tidak mendapat informasi terkait perawatan diri pada saat dismenore atau self care , 5 orang lebih memilih beristrirahat dan tidur-tiduran saja dan tidak melakukan aktivitas dan olahraga saat mengalami dismenore (50\%), 3 orang $(20 \%)$ lebih memilih meminum obat 
pereda nyeri dan obat penambah darah saat nyeri menstruasi, dan sisanya hanya meminum air hangat dan melakukan kompres hangat saat mengalami dismenore (30\%), 7 orang $(70 \%)$ menyatakan bahwa pernah istirahat ke UKS ketika mengalami dismenore atau nyeri haid disekolah. Sekolah sebenarnya mempunyai UKS tapi program UKS belum ada yang menekankan pada penatalaksanaan perawatan diri secara mandiri lengkap saat mengalami dismenore atau nyeri pada saat menstruasi.

Berdasarkan hal tersebut perlu dilakukan penelitian tentang pengaruh edukasi menstruasi melalui WhatsApp terhadap self care dismenore pada remaja putri SMA di Kota Bengkulu.

\section{METODE PENELITIAN}

Penelitian ini merupakan penelitian kuantitatif dengan rancangan quasy experiment (eksperimen semu) dengan pretest-postest with control group design. Kelompok intervensi diberikan perlakuan berupa edukasi melalui WhatsApp Populasinya adalah seluruh siswi SMA Negeri 02 dan SMA Negeri 05 di Kota Bengkulu. Kriteria inklusinya adalah remaja putri yang telah mengalami menstruasi usia 15-17 tahun, remaja putri yang mengalami dismenore, remaja putri sma kela X-XI, mampu berkomunikasi dengan baik dan mempunyai pendengaran yang baik dan memiliki smartphone dengan aplikasi WhatsApp. Kriteria eklusinya adalah responden tidak membaca informasi yang diberikan melalui WhatsApp sebanyak 3 kali, responden keluar dari grup WhatsApp dan responden sakit atau dirawat dirumah sakit.

Pada penelitian ini jumlah sampel sebanyak 35 orang untuk kelompok intervensi (perlakuan edukasi melalui WhatsApp) dan 35 orang untuk kelompok control (perlakuan link informasi). Total responden berjumlah 70 orang. Teknik sampling yang digunakan adalah simple random sampling.

Edukasi melalui WhatsApp merupakan suatu proses pemberitahuan atau penyebarluasan informasi melalui media sosial menggunakan aplikasi WhatsApp meliputi foto, chat, dan vidio mengenai dismenore, penanganan, dan perawatan diri saat dismenore yang akan diobservasi pada awal dan akhir penelitian.

Sebelum diberikan edukasi melalui WhatsApp remaja putri dilakukan pretest terlebih dahulu untuk melihat self care dismenore awal. Edukasi melalui WhatsApp dilakukan selama 2 minggu dan dilakukan pemberian materi dengan topik pembasan berbeda setiap harinya. Posttest dilakukan satu periode menstruasi selanjutnya.

Instrument penelitian berupa kuisioner ADSCS yang berisi tentang perawatan mandiri dalam meredakan dismenore meliputi mencari ilmu, ekspresi emosi, mencari bantuan, kontrol atas faktor ekstrenal, pemanfaatan sumber daya dan kontrol diri. Kuisioner penelitian ini menggunakan skala Likert bentuk check list. Kuisoner terdiri dari 35 pernyataan mengenai self care dismenore. Media edukasi berupa media sosial WhatsApp.

\section{HASIL}

Penelitian dilaksanakan di SMA Negeri 02 dan SMA Negeri 05. SMAN 02 Kota Bengkulu untuk kelompok intervensi dan SMAN 05 Kota Bengkulu untuk kelompok

\section{Tabel 1. Gambaran karakteristik responden}




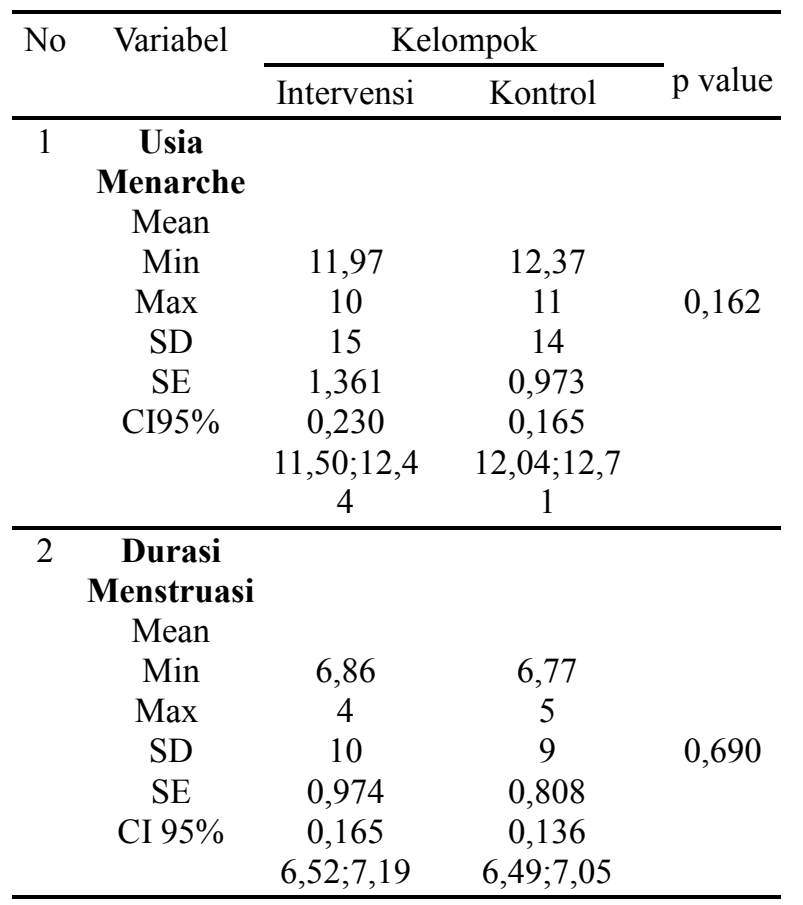

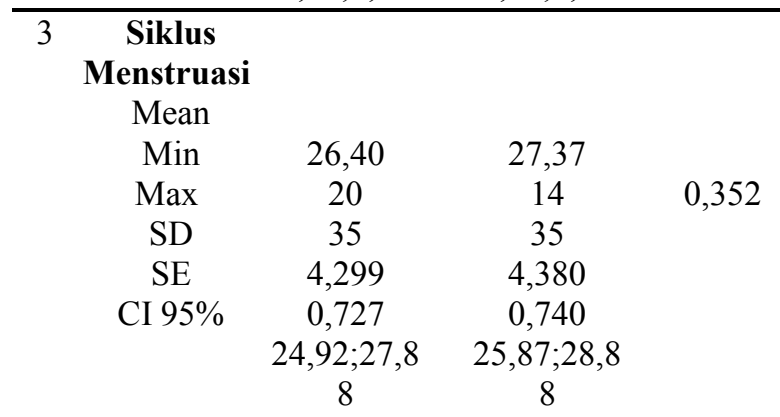

4 Pendidikan

orang tua

Dasar

\begin{tabular}{cccc} 
& 3 & 0 & \\
Menengah & $(8,6 \%)$ & $(0,0 \%)$ & 0,201 \\
& 12 & 12 & \\
Perguruan & $(34,3 \%)$ & $(34,3 \%)$ & \\
Tinggi & 20 & 23 & \\
& $(57,1 \%)$ & $(65,7 \%)$ & \\
\hline
\end{tabular}

5 Skala nyeri

Ringan

$\begin{array}{ccc} & 14 & 9 \\ \text { Sedang } & (40 \%) & (25,7 \%)\end{array}$

\begin{tabular}{cccc} 
& 18 & 18 & 0,186 \\
Berat & $(51,4 \%)$ & $(51,4 \%)$ & \\
& 3 & 8 & \\
& $(8,6 \%)$ & $(22,9 \%)$ & \\
\hline
\end{tabular}

Uji normalitas dilakukan dengan menggunakan metode skweness dibagi standar error. Uji statistic yang digunakan adalah uji non parametric (uji Mann whitney)

Tabel 2 Distribusi rata-rata self care dismenore sebelum dan sesudah dilakukan intervensi pada kelompok intevensi dan kontrol

\begin{tabular}{cccccc}
\hline Variabel Mean & $\begin{array}{c}\text { Min- } \\
\text { Max }\end{array}$ & SD & SE & $\begin{array}{c}\text { P value } \\
\text { dalam } \\
\text { kelompo } \\
\text { value } \\
\text { antar } \\
\text { kelo } \\
\text { mpok }\end{array}$ \\
\hline
\end{tabular}

Self care dismenore sebelum dilakukan edukasi WhatsApp

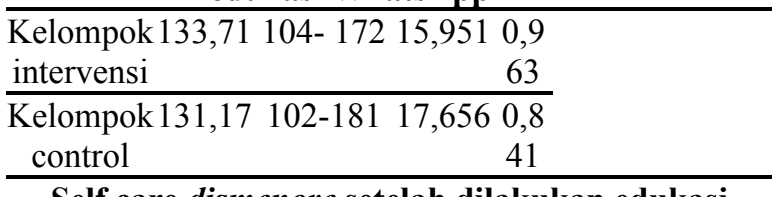

Self care dismenore setelah dilakukan edukasi WhatsApp

\begin{tabular}{llrrrr}
\hline Kelompok 150,09 & $120-185$ & 5,202 & 2,4 & $0,000^{*}$ & \\
Intervensi & & & 73 & & \\
\cline { 1 - 4 } Kelompok 134,57 & $99-191$ & 9,046 & 3,2 & 0,004 & 0,000 \\
kontrol & & & 92 & & $*$
\end{tabular}

$\mathrm{P}$ value sesudah dilakukan edukasi melalui WhatsApp, pada kelompok intervensi sebesar 0,000* yang diartikan bahwa ada perbedaan self care dismenore sebelum dan sesudah diberikan edukasi melalui WhatsApp sedangkan $\mathrm{p}$ value pada kelompok control 0,004 yang diartikan ada perbedaan self care dismenore sebelum dan sesudah diberikan edukasi melalui WhatsApp. Hasil uji statistik Mann Whitney menunjukkan nilai $\mathrm{p}$ value sebesar $0,000(\mathrm{p} \leq \alpha=0,05)$ dapat disimpulkan ada pengaruh edukasi melalui WhatsApp terhadap peningkatan nilai rata- dismenore sebelum dan sesudah dilakukan intervensi edukasi melalui WhatsApp siswi SMAN 02 dan SMAN 05. Intervensi edukasi WhatsApp dapat meningkatkan nilai rata-rata self care dismenore siswi SMAN 02 dan SMAN 05.

Tabel 3 Perbedaan self care dismenore sebelum dan sesudah edukasi WhatsApp

\begin{tabular}{cccccc} 
Variabel & Mean & $\begin{array}{c}\text { Min- } \\
\text { Max }\end{array}$ & SD & SE & P value \\
\hline $\begin{array}{c}\text { Kelompok } \\
\text { intervensi }\end{array}$ & 16,37 & $7-30$ & 5,202 & 0,879 & $0,000^{*}$ \\
\hline $\begin{array}{c}\text { Kelompok } \\
\text { control }\end{array}$ & 3,40 & $-32-22$ & 9,046 & 1,529 & \\
\hline
\end{tabular}


Hasil uji statistic menggunakan Mann Whitney didapatkan nilai $p$ value 0,000 sehingga dapat diartikan bahwa ada perbedaan nilai rata-rata self care dismenore sebelum dan sesudah dilakukan intervensi edukasi melalui WhatsApp siswi SMAN 02 dan SMAN 05. Intervensi edukasi WhatsApp dapat meningkatkan nilai rata-rata self care dismenore siswi SMAN 02 dan SMAN 05.

\section{PEMBAHASAN}

Hasil penelitian ini menunjukkan Peningkatan rata-rata self care dismenore setelah diberikan intervensi melalui media sosial WhatsApp yaitu dengan rata-rata skor self care dismenore 150,09 dengan $\mathrm{p}$ value 0,000 yang diartikan bahwa ada perubahan self care dismenore setelah diberikan edukasi melalui WhatsApp. Sedangkan rata-rata self care dismenore pada kelompok kontrol yaitu 134,57 dengan $p$ value $0,004 *$ yang diartikan bahwa terdapat perubahan setelah diberikan link informasi. Hal ini sejalan dengan penelitian (Issuryanti,2017) dimana menunjukkan bahwa terdapat peningkatan pengetahuan yang signifikan dalam memberikan ASI Ekslusif setelah dibeikan edukasi melalui WhatsApp dengan $(\mathrm{p}<0,05)$. Hasiluji statistik didapatkan nilaip value sebesar $0.000(p<\alpha) \alpha=0.05$ sehingga dapat disimpulkan hipotesis di terima bahwaa dapengaruh edukasi melalui WhatsApp terhadap self care dismenore pada remaja putri SMAN 02 DAN SMAN 05 Kota Bengkulu.

Edukasi melaui WhatsApp telah terbukti bermanfaat untuk belajar karena meningkatkan partisipasi siswa dalam konteks tatap muka dan jarak jauh antara siswa, siswa lain, dan pendidik (Johnson et al., 2015;) Pemberian edukasi melalui WhatsApp pada penelitian ini dilakukan selama 2 minggu. Edukasi melalui media elektronik dapat meningkatkan self care dismenore. Makoe 2012; Nicholson 2002; Rambe \& Bere 2013). Hal ini sejalan dengan penelitian (Issuryanti,2017) dimana menunjukkan bahwa terdapat peningkatan pengetahuan yang signifikan dalam memberikan ASI Ekslusif setelah dibeikan edukasi melalui WhatsApp dengan $(p<0,05)$.Edukasi menggunakan whatspp juga terbukti dapat meningkatkan kemampuan berpikir kritis pada siswa dan whatsapp messenger sebagai mobile learning terintegrasi yang efektif untuk diterapkan dalam pembelajaran dan meningkatkan kemampuan berpikir kritis karena dengan media sosial wa membuat siswa termotivasi dan tertarik mengikutipembelajaran (hendrik, 2016). Efektifitas penerapan pembelajaran whatsapp dapat meningkatkan skor keterampilan berpikir kritis karena whatsapp dapat membuat siswa belajar secara terbuka menyampaikan pendapat, interaktif, dan dapat memperoleh jawaban dari setiap permasalahan dengan cepat (Winda,dkk 2015). Edukasi melalui media whatsapp juga terbukti dalam peningkatan pengetahuan penanganan pertama cidera muskuloskeletal pada pelatih sepakbola dengan nilai $\mathrm{p} 0,000$ (Wibisono,2017). Hal ini dikarenakan media sosial whatsapp merupakan media sosial populer yang banyak digunakan dalam pemberian informasi dan edukasi berbagai ilmu karena banyak Studi juga mengatakan tentang penggunaan teknologi yang sedang berkembang dan pembelajaran mobile untuk meningkatkan pembelajaran siswa menjadi lebih baik salah satunya whats App (Bozalek et al 2015).

\section{KESIMPULAN}

Berdasarkan hasil penelitian dapat diambil kesimpulan bahwa :

1. Media sosial WhatsApp dapat meningkatkan self care dismenore pada remaja putri.

2. Edukasi melalui media sosial WhatsApp merupakan salah satu media alternative dalam proses pemberian informasi kesehatan mengenai menstruasi dan self care dismenore untuk remaja putri. 


\section{SARAN}

Sekolah sebaiknya memanfaatkan media WhatsApp dalam proses pemberian informasi kesehatan dan membuat learning grup diskusi tentang praktek self care dismenore.

\section{DAFTAR PUSTAKA}

Agarwal, A., \& Venkat, A. (2009). Questionnaire study on menstrual disorders in girls in Singapore. Journal of Pediatric Adolescents \& Gynecology, 22(6), 365371.

Bozalek, V., Ng'ambi, D., Wood, D., Herrington, J., Hardman, J. \& Amory, A. (eds.), (2015), Activity theory, authentic learning and emerging technologies: Towards a transformative higher education pedagogy, Routledge, London and New York.

Cry P, Taylor R, Skelton A.Menstrual disorder in family medicine principles and practice. $6^{\text {th }}$ ed., library of cengress cataloging, 2003;880

Cheng, J. F., Lu, Z. Y., Su, Y.C., Chiang, L. C., \& Wang, R.Y. (2008).A traditional Chinese herbal medicine used to treat dysmenorrhea among Taiwanese women. Journal of Clinical Nursing, 17, 25882595.

Gustina (2015). Sumber Informasi dan Pengetahuan Tentang Menstuasi Hygiene Pada Remaja Putri. Jurnal Kesehatan Masyarakat 10 (2) , 147-152

Isnaeni, D. N. (2010). Hubungan antara stres dengan pola menstruasi pada mahasiswa DIV kebidanan jalur reguler Unibersitas Sebelas Maret. Surakarta.

Orem, D. E. (2001). Nursing: Concepts of practice (6th ed.). St. Louis, MO: Mosby

Proverawati,A.(2012). Menarche Menstruasi Pertama Penuh Makana. Yogyakarta : Mutia Medika

Wibisono, Y. (2007). Membedah Konsep dan Aplikasi CSR. Fascho Publising, Surabaya. 